\title{
Refractory relapsing polychondritis: challenges and solutions
}

This article was published in the following Dove Press journal: Open Access Rheumatology: Research and Reviews

\author{
Fernando Kemta Lekpa ${ }^{1,2}$ \\ Xavier Chevalier ${ }^{3}$ \\ 'Faculty of Health Sciences, University \\ of Buea, Buea, ${ }^{2}$ Reheumatology Unit, \\ Internal Medicine Department, \\ General Hospital, Douala, Cameroon; \\ ${ }^{3}$ Department of Rheumatology, Henri \\ Mondor Hospital, University Paris I2, \\ Créteil, France
}

Correspondence: Xavier Chevalier Department of Rheumatology, Henri Mondor Hospital, 5I Avenue du Maréchal de Lattre de Tassigny, 94010 Créteil, France

Tel +33 | 498 I 270 I

Fax +33 | 498| 4703

Email xavier.chevalier@hmn.aphp.fr

\begin{abstract}
Relapsing polychondritis is a severe systemic immune-mediated disease characterized by an episodic and progressive inflammatory condition with progressive destruction of cartilaginous structures. This disease has for nearly a century kept secrets not yet explained. The real incidence and prevalence of this rare disease are unknown. The multiple clinical presentations and episodic nature of relapsing polychondritis cause a significant diagnosis delay. No guidelines for the management of patients with relapsing polychondritis have been validated to date. The challenges remain, both in the understanding of its pathophysiology and diagnosis, evaluation of its activity and prognosis, and its treatment. Possible solutions involve the sharing of data for relapsing polychondritis from worldwide reference centers. Thus, we would be able to evolve toward a better knowledge of its pathophysiology, the publication of new diagnosis criteria, which will include biological markers and imaging findings, the prediction of life-threatening or organ-threatening situations, and the publication of therapeutic evidence-based guidelines after performing at randomized controlled trials.
\end{abstract}

Keywords: relapsing polychondritis, diagnosis, criteria, disease activity, treatments, biologics

\section{Introduction}

Relapsing polychondritis is a severe systemic immune-mediated disease characterized by episodic and progressive inflammatory condition with progressive destruction of cartilaginous structures, particularly widespread chondritis of the ears, nose, laryngotracheo-bronchial tree, and joints. Proteoglycans-rich structures such as the eyes, heart, blood vessels, inner ears, and skin may also be concerned. Relapsing polychondritis may be isolated or associated with other disorders. ${ }^{1-5}$

In 1923, Jaksch Wartenhorst published the first description and gave the name of polychondropathy to this disease. ${ }^{6}$ In 1960 , Pearson et al proposed its currently accepted name, "relapsing polychondritis", in a description of 4 cases and review of 12 previous cases. These authors clearly identified relapsing polychondritis as an intense inflammatory condition of both cartilaginous and non-cartilaginous tissues. They also observed that the progress after some episodes of inflammation was marked by a replacement of the cartilage with fibrous connective tissue. ${ }^{7}$ Three sets of criteria have been published. ${ }^{8-10}$ The disease has continued to intrigue the scientific community because of its rarity, unknown etiopathogenesis, clinical polymorphism, unpredictable evolution, and uncodified treatment. Thus, despite the scientific progress and a clearer knowledge of relapsing polychondritis, the challenges of the last century still continue to exist. 


\section{Epidemiology challenges: is this really a rare disease?}

About one thousand cases of relapsing polychondritis have been published to date, making this entity a rare disease. Most of the published cases are from the case series form specialized centers. Cases series of more than 100 patients are rare.$^{10-13}$ Thus, the real incidence and prevalence of relapsing polychondritis are unknown. A large disparity exists in the few available data. The annual incidence was estimated at 3.5 per million person-years in Rochester, MN, USA. ${ }^{14} \mathrm{~A}$ recent Hungarian study confirms these data. ${ }^{15}$ However, a population-based cohort study conducted in the United Kingdom found a lower annual incidence, estimated at 0.71 per million person-years. The same study estimated the prevalence of relapsing polychondritis and estimated it at 9.0 cases per million population. ${ }^{16}$ The prevalence is estimated at 4.5 cases per million in a military population in the United States. ${ }^{17}$

Relapsing polychondritis has a ubiquitous distribution with documented cases in all ethnic groups, but most patients appear to be of Caucasian origin. ${ }^{1-3}$ It seems exceptional among SubSaharan Africans. ${ }^{18,19}$ Family cases are rare. Female predominance is increasingly found, but several studies have not found any sex difference. However, relapsing polychondritis does not appear to affect fertility and the development of pregnancy. The age of predilection at diagnosis varies between the fourth and fifth decades, but it may occur at any age. ${ }^{1-5}$

The generalization of these data requires performing population-based studies like in recent epidemiological studies carried out in Hungary ${ }^{15}$ and the United Kingdom. ${ }^{16}$ Many others population-based studies are necessary to confirm the data currently available, particularly due to the scarcity of relapsing polychondritis.

\section{Etiopathogenesis challenge: the Achilles heel}

The etiology of relapsing polychondritis remains unknown. Pathophysiology is uncertain, and causes of flares are also unknown. No specific factor or environmental risk exposure has been identified to date. Relapsing polychondritis has been also regarded as an autoimmune disease (due to the presence of some autoantibodies notably anti-collagen type 2 autoantibody). Relapsing polychondritis results probably from a combination of a genetic susceptibility, a triggering factor, and a subsequent abnormal autoimmune reaction. ${ }^{1-5}$

The triggering and aggressive factors can be of multiple origins: chemical, toxic, infectious, or traumatic agents. Cases reports of relapsing polychondritis after a trauma of the pinna, ${ }^{20,21}$ per os intake of chondroitin-glucosamine, ${ }^{22}$ and intravenous intake of toxin have been published..$^{23}$ Thus, there may be a direct link between these factors and the onset of autoimmune process. ${ }^{24}$

Connective tissue diseases and systemic vasculitis have been associated with relapsing polychondritis, suggesting an immune-associated condition (Table 1). A genetic link between HLA-DR4 antigen and relapsing polychondritis has been described in Caucasians. ${ }^{25,26}$ The incidence of HLA-DR4 was greater than $56 \%$ in patients with relapsing polychondritis compared with $26 \%$ in the control group of healthy patients. ${ }^{26}$ While specific alleles of HLA-DR4 were identified in genetic susceptibility of rheumatoid arthritis, none was observed in relapsing polychondritis. ${ }^{25,26}$ In a Japanese study, HLA-DRB1*16:02, HLA-DQB1*05:02, and HLA-B*67:01 were associated with susceptibility to relapsing polychondritis, suggesting a susceptibility to HLA class II. ${ }^{27}$ The cartilage in relapsing polychondritis is infiltrated by numerous inflammatory cells such as neutrophils and lymphocytes: CD4 + natural killer T (NKT) cells (NKT cells with two types: CD4 + and CD4-/CD8, a new type of lymphocytes different from others $[\mathrm{T}, \mathrm{B}, \mathrm{NK}]$ ), which play a major role in the T1-helper response. ${ }^{28}$ Among the different cytokines produced in the inflamed tissue, interleukin 8 , monocyte chemoattractant protein-1, and macrophage inflammatory protein 1-alpha were the most elevated. Thus, a cell-mediated immune response could have a pivotal role in the pathogeny of relapsing polychondritis. ${ }^{29}$ Otherwise, autoantibodies

Table I Systemic vasculitis and connective tissue disorders associated with relapsing polychondritis (not exhaustive)

\begin{tabular}{ll}
\hline Systemic vasculitis & $\begin{array}{l}\text { Behçet's disease (MAGIC syndrome), granulomatosis with polyangiitis, polyarthritis nodosa, Churg and } \\
\text { Strauss's syndrome }\end{array}$ \\
Connective tissue diseases & $\begin{array}{l}\text { Sjögren's syndrome, rheumatoid arthritis, systemic lupus erythematosus, mixed connective tissue diseases, } \\
\text { systemic sclerosis }\end{array}$ \\
Spondyloarthritis & Ankylosing spondylitis, psoriatic arthritis, reactive arthritis, inflammatory bowels diseases \\
Other autoimmune diseases & Autoimmune thyroiditis, type I diabetes, familial Mediterranean fever, myasthenia gravis, primary biliary \\
cirrhosis & Myelodysplastic syndromes, lymphomas, myeloproliferative neoplasms, thymoma \\
Dermatosis & Sweet's syndrome, neutrophilic dermatosis, pyoderma gangrenosum, leukocytoclastic vasculitis, psoriasis
\end{tabular}

Abbreviation: MAGIC, mouth and genital ulcers with inflamed cartilage 
directed against cartilage matrix components may also play a central role in the pathophysiology of relapsing polychondritis. Autoantibodies directed against collagen type 2 are present in acute flare of relapsing polychondritis and their serum levels correlates with the severity of relapses. ${ }^{30-33}$ Other autoantibodies, anti-collagen type IX and XI, have been detected but their exact role needs to be established. ${ }^{28,33}$ Anti-matrilin-1 autoantibody (directed matrilin-1, an extracellular matrix protein found mainly in tracheal cartilage) was of particular value since it is significantly elevated during respiratory flares of the disease, and because immunization with matrilin-1 in animal model seems to reproduce the disease. ${ }^{34-38}$ However, all these autoantibodies are neither sensitive nor specific for relapsing polychondritis. ${ }^{34-37}$ Thus, the pathogenic value of those different autoantibodies is still not established in humans. ${ }^{28,30-36,38}$ A cross-reactivity and a mechanism of molecular mimicry with an immune reaction triggered by microorganisms and then directed against a component of the cartilage matrix is an attractive hypothesis. Several antigenic similarities between some components of the cartilage matrix such as proteoglycans and peptidoglycans of Streptococcus sp., proteins derived from other molecules such as Mycobacterium tuberculosis, heat-shock protein 60, and some particle of Myxoma virus have been evidenced. ${ }^{39-41}$

Nevertheless, all those relevant pathogenic hypotheses need to be confirmed. The problem we are facing with is that we have no reliable animal model of relapsing polychondritis. And because the disease is rare, it is important to recruit larger number patients in any study, which underlines the necessity of international collaborative works.

\section{Clinical manifestations: a real bazaar!}

Relapsing polychondritis is a disorder evolving by flare remission. It is characterized by clinical polymorphism, requiring a team approach with different medical and surgical specialties. The onset of the disease is generally brutal and acute. The most common initial clinical picture is chondritis of ears associated with pain, erythema, and edema, followed by chondritis of nose (Figure 1). Chondritis of chondro-costal joints and upper airways, scleritis and episcleritis, arthralgia, and various mucocutaneous lesions can subsequently occur. Repeated inflammation can lead to the destruction of the cartilage and deformity of the nose, ears and respiratory tract. Tracheobronchomalacia and ascending aorta involvement are the most feared complications. Fever, asthenia, weight loss, or rash may be inaugural symptoms. Rheumatologic involvement varies from simple arthralgia to asymmetric, migratory, and non-erosive arthritis of small and large joints, with a predilection for chondro-costal joints. All of these manifestations generally occur gradually with time and their frequency varies with disease duration, activity, and severity (Table 2). This clinical heterogeneity is a source of

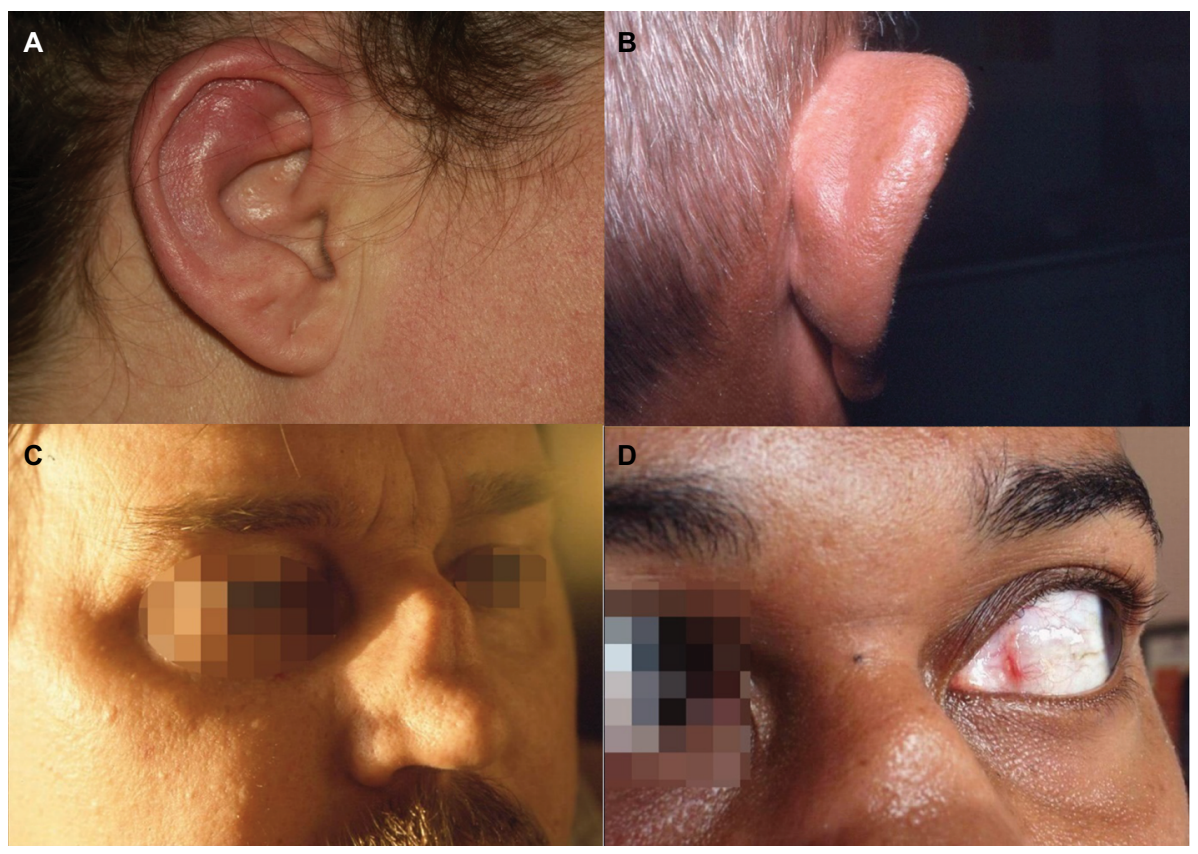

Figure I Relapsing polychondritis: auricular chondritis during acute phase (A); chronic phase with collapse of the cartilage of the upper pole of the ear (B); saddle nose deformity (C); episcleritis (D).

Note: Reproduced with permission from Club Rhumatismes et Inflammations. [website on the Internet]. Available from http://www.cri-net.com/autres-projets/base_images/ display_rub.asp?rub=poly_atro. ${ }^{79}$ 
Table 2 Comparison of demographics and clinical features of 10 cohorts around the world

\begin{tabular}{|c|c|c|c|c|c|c|c|c|c|c|}
\hline & $\begin{array}{l}\text { McAdam } \\
\text { et } \mathbf{a l}^{8} \\
\text { (USA) }\end{array}$ & $\begin{array}{l}\text { Michet } \\
\text { et al }{ }^{10} \\
\text { (USA) }\end{array}$ & $\begin{array}{l}\text { Zeuner } \\
\text { et al }{ }^{25} \\
\text { (Germany) }\end{array}$ & $\begin{array}{l}\text { Trentham } \\
\text { and Le } \text { 5* }^{\text {(USA) }} \\
\text { (USA }\end{array}$ & $\begin{array}{l}\text { Mathew } \\
\text { et al }{ }^{17} \\
\text { (USA) }\end{array}$ & $\begin{array}{l}\text { Sharma } \\
\text { et } \mathrm{al}^{3} \\
\text { (India) }\end{array}$ & $\begin{array}{l}\text { Shimizu } \\
\text { et } \text { al }^{42} \\
\text { (Japan) }\end{array}$ & $\begin{array}{l}\text { Lin } \\
\text { et } \mathrm{al}^{12} \\
\text { (China) }\end{array}$ & $\begin{array}{l}\text { Dion } \\
\text { et al }{ }^{13} \\
\text { (France) }\end{array}$ & $\begin{array}{l}\text { Pallo } \\
\text { et } \text { al }^{54} \\
\text { (Brazil) }\end{array}$ \\
\hline Number of patients (n) & 159 & 112 & 62 & 66 & 43 & 26 & 239 & 158 & 142 & 30 \\
\hline $\begin{array}{l}\text { Mean age at diagnosis } \\
\text { (years) }\end{array}$ & 44 & 51 & 46 & 46 & 44 & 45 & 53 & 45 & 43 & 49 \\
\hline Female/male (n) & $76 / 83$ & $55 / 57$ & $26 / 63$ & $49 / 17$ & $23 / 20$ & $16 / 10$ & $112 / 127$ & $63 / 95$ & $86 / 56$ & $21 / 9$ \\
\hline Mean follow-up (months) & NR & 72 & 12 & 96 & 84 & NR & 64 & NR & 156 & 72 \\
\hline Auricular chondritis (\%) & 89 & 85 & 93 & 95 & 88 & 96 & 78 & 68 & 89 & 100 \\
\hline Hearing impairment (\%) & 46 & 30 & 19 & 42 & 37 & 42 & 27 & 25 & 27 & 30 \\
\hline $\begin{array}{l}\text { Laryngotracheal } \\
\text { involvement (\%) }\end{array}$ & 56 & 48 & 30 & 67 & 37 & II & 50 & 69 & 43 & 57 \\
\hline Nasal chondritis (\%) & NR & 29 & 56 & 20 & 35 & 81 & 39 & 54 & 63 & 10 \\
\hline Arthritis (\%) & 81 & 52 & 53 & 85 & 60 & 54 & 39 & 18 & 69 & 60 \\
\hline Ocular involvement (\%) & 65 & 51 & 50 & 57 & 57 & 42 & 46 & 44 & 56 & 37 \\
\hline $\begin{array}{l}\text { Cardiovascular } \\
\text { involvement (\%) }\end{array}$ & 9 & 6 & 22 & 8 & 27 & II & 7 & 10 & 22 & 3 \\
\hline Skin involvement (\%) & 17 & 28 & 24 & 38 & NR & 26 & 14 & 46 & 29 & NR \\
\hline
\end{tabular}

Note: *Based on 36 patients with relapsing polychondritis and 30 patients from literature review.

Abbreviation: NR, not recorded.

diagnostic errors, particularly since the initial manifestations in a given patient are extra-chondritic and clinical ignorance of this rare disease..$^{1-5}$

The difficulty is often not to evoke the diagnosis of relapsing polychondritis in presence of nasal or ear chondritis. The differential diagnosis concerns more each organ involvement that may appear immediately in a given patient but most of the time appears gradually with an average of 2 symptoms at the onset of the disease. ${ }^{13}$ When rheumatologic involvement precedes auricular and nasal chondritis (and/or when episodes of chondritis have been neglected), the diagnosis of relapsing polychondritis becomes very difficult, not to say impossible because few clinicians would include relapsing polychondritis in diagnoses to be evoked in front of a patient with arthritis.

Once the differential diagnoses have been eliminated, the next step is to make a distinction between symptoms and signs associated with relapsing polychondritis and those related to possible associated diseases, as presented in Table $1 .{ }^{1-5}$ Indeed, one-third of patients with relapsing polychondritis have an intercurrent disease including systemic vasculitis and inflammatory or hematological diseases. Theses concomitant disease may precede, occur after, or present simultaneously with relapsing polychondritis. ${ }^{1-5,13}$ Establishing the diagnosis early is a challenge when relapsing polychondritis or systemic vasculitis is suspected. Indeed, differential diagnosis can be difficult between relapsing polychondritis and systemic vasculitis (particularly ANCA positive-vasculitis like granulomatosis with polyangiitis) in view of common clinical and immunological features between these two nosological entities. ${ }^{13,41}$ The pitfall is the same in patients with Behçet's disease. Moreover, there is an overlap syndrome between Behçet's disease and relapsing polychondritis called the MAGIC syndrome. ${ }^{42}$ Chondritis is a common feature of Lupus disease. Auricular chondritis cases have been described in patients with leprosis, simulating relapsing polychondritis, particularly if arthritis is present. Skin biopsy helps the diagnosis by showing a granuloma with the presence of acid-fast bacilli. ${ }^{43}$ Otherwise, a specific relationship exists between relapsing polychondritis and myelodysplastic syndromes. Myelodysplastic syndromes occur in approximately $8-40 \%$ of patients with relapsing polychondritis, mostly in men over 60 years of age. ${ }^{1-5,13}$ Other hematological malignancies such as lymphomas may be associated.

The distinction between renal involvements associated with relapsing polychondritis and associated diseases like systemic vasculitis or systemic lupus erythematosus raises many questions. Renal feature is involved in up to $22 \%$ of patients in certain series of patients with relapsing polychondritis. It was characterized by an elevation of serum creatinine, proteinuria, and hematuria. Renal biopsy may show mild mesangial expansion and cell proliferation, segmental necrotizing glomerulonephritis with crescents, segmental mesangial proliferation, vascular and glomerular sclerosis, tubular loss, and interstitial lymphocytic infiltrates. Immunofluorescence has revealed faint deposition of $\mathrm{C} 3 \mathrm{and} /$ or IgG or IgM, predominantly in the mesangium. ${ }^{41,44}$ Dion et a ${ }^{13}$ did not find any renal damage in their series. The better knowledge of 
the positive ANCA vasculitis makes it possible to distinguish between relapsing polychondritis and granulomatosis with polyangiitis, even if there was a nasal involvement, classic during this systemic vasculitis. Thus, many patients with renal involvement and chondritis would be misclassified as having relapsing polychondritis instead of granulomatosis with polyangiitis or may have both associated diseases. ${ }^{13,41}$

\section{Diagnostic challenge: toward new criteria?}

The multiple clinical presentations and episodic nature of relapsing polychondritis cause a significant diagnosis delay, ranging from 1.9 to 10 years with an average of five physicians to be consulted before the diagnosis is made..$^{5,16}$

No laboratory or imaging tests are specific. Indeed, there are no biomarkers to assess for ongoing cartilage damage. The main aim of blood tests is to look for associated diseases, some of which are also part of the differential diagnosis. Cartilage biopsy is not essential to diagnosis but may contribute to it in the early, atypical, or frustrating forms of the disease. The destruction of cartilage with proteoglycan depletion in relapsing polychondritis is induced on one hand by a pleomorphic perichondral infiltrate of lymphocytes, polymorphonuclear cells, monocyte/macrophages, and plasma cells, and on the other hand by intrinsic factors such as certain types of proteolytic and apoptotic enzymes (particularly matrix metalloproteinases-3 and cathepsin-K) expressed in chondrocytes. ${ }^{45,46}$ Imaging techniques such as computed tomography (CT), magnetic resonance imaging (MRI), scintigraphy (with technetium-99m methylene diphosphonate or gallium-67 citrate), and Doppler echocardiography reveal anomalies of the laryngo-tracheo-bronchial tree and aorta. ${ }^{1-5,47}$ Numerous studies have shown the value of fluorine-18 fludeoxyglucose positron emission tomography as a new diagnosis modality that may be helpful in early disease recognition, early diagnosis of relapsing polychondritis, as well as detection of subclinical chondritis, evaluation of disease activity, disease extension, site for targeted biopsy, and therapeutic response monitoring. ${ }^{48-52}$ Then, the presence of symmetrically distributed high fluorine-18 fludeoxyglucose uptake lesions at two or more cartilages may be a new criterion for the diagnosis. ${ }^{48}$

Current diagnosis of relapsing polychondritis is clinical. In the presence of an evocative symptomatology, the clinician can use the diagnosis criteria established over the years by McAdam et al, ${ }^{8}$ Damiani and Levine, ${ }^{9}$ Michet et al. ${ }^{10}$ The McAdam et al's criteria ${ }^{8}$ require at least three criteria out of six of the following: 1) bilateral auricular chondritis,
2) non-erosive seronegative polyarthritis, 3) nasal chondritis, 4) ocular inflammation, 5) respiratory tract chondritis, and 6) cochlear and/or vestibular dysfunction. Damiani and Levine ${ }^{9}$ expanded these criteria, which include meeting one of McAdam et al's criteria plus histological confirmation and/or efficacy to corticosteroids or dapsone. The diagnosis of relapsing polychondritis relies mostly on Michet et al's criteria, which do not require biopsy but require the presence of a proven chondritis in at least two of three of the auricular, nasal or, laryngotracheal cartilages, or chondritis in one of these cartilage plus two other signs, including ocular inflammation, vestibular dysfunction, seronegative inflammatory arthritis, and hearing loss. ${ }^{10}$ These criteria ${ }^{8-10}$ have the merit to facilitate the practice of clinicians who deal with relapsing polychondritis. However, they have limitations. Firstly, these criteria were established on single-center cohorts with a limited number of patients; 112 patients for Michet et al's criteria $^{10}$ and significantly less for the criteria of McAdam et $\mathrm{al}^{8}$ and Damiani and Levine, ${ }^{9} 23$ and 10 patients, respectively. Secondly, none of these studies had a specific design for establishing diagnostic or classification criteria. Thirdly, none of these criteria has been validated in an independent cohort. This summarizes all the problems of a rare disease with publications that are essentially monocentric. It is necessary that the teams that support the relapsing polychondritis put together their database in order to have a high number of patients and therefore evolve towards new criteria.

These new criteria should consider: 1) diagnosis and classification; 2) early diagnosis; 3 ) integration of the progressive nature of clinical presentation; 4) to determine the place, also surrogate diagnostic biological markers and imaging findings; and 5) to determine whether clinical response to corticosteroids still have a place in the diagnosis and/or classification of relapsing polychondritis, which appears much more fragile.

\section{Evolution and prognosis challenge: an unpredictable disease activity!}

The evolution of relapsing polychondritis is very often unpredictable. In a recent study, no correlations were found between clinical features, acute phase reactants, and imaging findings. ${ }^{53}$ Most patients have a low disease activity, with multiple flares. These relapses usually involve the same site, accompanied by progressive destruction of the cartilage, causing a growing disability or even destruction or loss of function (hearing loss, decreased visual acuity, dysphonia, cardiopulmonary events). The major risk is the death of the patient. Michet et $\mathrm{al}^{10}$ had shown that in patients younger 
than 51 years, age, saddle nose deformity, laryngotracheal involvement, arthritis, systemic vasculitis, and hematuria were the predictors of a poor prognosis. In older patients, only anemia predicts a worse outcome. In a French cohort, male sex, cardiac involvement, myelodysplasia, and other associated hematological malignancies were the main factors associated with death. ${ }^{13}$ In the United Kingdom, old age, respiratory and cardiac complications, and cancer were associated with death. ${ }^{16}$ In a Chinese cohort, the primary causes of death were respiratory failure, lung infections, and cardiovascular events. ${ }^{12}$ In Brazil, the worse prognosis was common in male patients than in female patients. Moreover, the prevalence of hypertension and diabetes mellitus was high in patients with relapsing polychondritis than in controls. ${ }^{54}$

Until recently, disease activity was assessed by the persistence of clinical symptoms and signs, acute phase reactants, and imaging techniques such as laryngoscopy, bone scintigraphy, and CT or MRI of the trachea. ${ }^{55,56}$ Biomarkers like urinary type II collagen neoepitope, ${ }^{55}$ cartilage oligomeric matrix protein, ${ }^{56}$ and soluble triggering receptor expressed on myeloid cells $-1^{57}$ might be of interest for assessing disease activity and could guide the therapeutic decision. ${ }^{55-57}$ Otherwise, a significant increase in the serum level of collagen type II collagenase cleavage neoepitope (marker reflecting degradation of collagen II under the effect of collagenases) may be present during the active phases in patients treated with corticosteroids. ${ }^{56}$ Furthermore, an association was found between HLA-DR6 and the severe clinical manifestations of relapsing polychondritis, but the clinical relevance of this link remains to be demonstrated. ${ }^{25}$ All these results must be confirmed by open studies, which are difficult to perform due to the scarcity of relapsing polychondritis and the heterogeneous nature of the clinical presentation.

In 2012, a worldwide panel of experts published a score of evaluation of the activity, the Relapsing Polychondritis Disease Activity Index (RPDAI). ${ }^{58}$ These experts rated the Physician's Global Assessment of Disease Activity of the real patients involved in the study who were diagnosed with relapsing polychondritis fulfilling Michet et al's criteria. ${ }^{10}$ The RPDAI, which is made of 27 items, is an advance in objective clinical assessment of disease activity (in a 28-day period) and response to treatment and requires extensive use in daily clinical practice and clinical trials. ${ }^{58}$

The RPDAI has the merit of being the first consensus scale to assess disease activity in relapsing polychondritis. Moreover, it will be an important contribution to homogenize the disease activity measurement between physicians and institutions. ${ }^{58}$ However, it needs to be improved by taking into account not only the clinical components but also the parameters of the acute phase reactants such as C-reactive protein (CRP) or erythrocyte sedimentation rate and the biomarkers involved in cartilage remodeling. In addition, emphasis should be made to each clinical manifestation, depending on its frequency and impact on patient survival. This is in line with the study by Dion et al, ${ }^{13}$ which identified 3 different phenotypes in relapsing polychondritis depending on clinical manifestations, disease progression, and prognosis. The first "hematologic" phenotype is characterized by the abundance of clinical manifestations, in particular the presence of a myelodysplastic syndrome, and the near absence of tracheobronchial involvement. Mortality was high in this group (58\%), and the intensive care units (ICU) admission was $50 \%$. The second "respiratory" phenotype is characterized by a high prevalence of laryngo-tracheo-bronchial chondritis and abnormal respiratory tests. No patient had myelodysplasia. These patients frequently received immunosuppressive agents and biologics. Mortality and ICU admission were lower (13\% and $27 \%$, respectively), but infection rates were high at $35 \%$. There is a third phenotype considered "mild". This phenotype is the most common. Hematological manifestations, trachebronchial involvement and other manifestations are rare. Mortality and ICU admission were very low ( $4 \%$ and $2 \%$, respectively). All patients with long-term remission were from this group. Moreover, the specific renal involvement of relapsing polychondritis would be rare or non-existent in this disease. ${ }^{13}$ Renal involvement found in patients with relapsing polychondritis would then be related to the association with ANCA-positive vasculitis. ${ }^{13,41}$ Renal features should therefore not be included in the RPDAI, where to a lesser extent it has the same impact as manifestations such as laryngo-tracheo-bronchial chondritis, cardiac involvement, and myelodysplastic syndrome. ${ }^{13}$ In addition, hematological involvement is not clearly reflected in the RPDAI, while myelodysplasia and other associated hematological malignancies have been identified as major causes of death in relapsing polychondritis. ${ }^{10,13}$ Changes to the RPDAI or the development of another activity score are a on waiting list in the future agenda.

There is evidence of improved global survival. Indeed, we have seen over the years this survival at 5 and 10 years go from $74 \%$ to $55 \%{ }^{10}$ some 40 years ago to $95 \%$ and $91 \%$ in $2012 .{ }^{12}$ This optimistic note is also found in other series. $^{15,16}$ There is a real hope that improvements in the technical set-up with better surgical techniques can help reduce the morbidity and mortality associated with relapsing polychondritis. 


\section{Treatment challenge: what place for evidence-based medicine?}

No guidelines for the management of patients with relapsing polychondritis have been validated to date. The rarity of this disease, heterogeneity of clinical presentation, and unpredictable occurrence of relapses partly explain the lack of understanding of etiopathogenesis and the failure to carry out a clinical trial to demonstrate the efficacy and safety of a treatment. Thus, the different therapeutic strategies currently used are all empirical and based on the reported cases. ${ }^{1-5,59}$

Despite the absence of clinical trials or validated recommendations, corticosteroids are the only drug that are unanimous in the management of patients with relapsing polychondritis. ${ }^{1,2}$ They are indicated for almost all manifestations of the disease at all stages. Prednisone or an equivalent is able to induce a complete remission in some patients. High-doses corticosteroids or intravenous pulse therapy are sometimes necessary during relapse, life-threatening, or organ-threatening situations. Inhaled corticosteroids appear to be effective in obstructive respiratory manifestations, which can be used to reduce systemic doses of corticosteroids. Intralesional corticosteroids are also an option for localized cutaneous involvement without visceral involvement. 2,60 Continual intratympanic corticosteroids injection could be effective in sensorineural hearing loss. ${ }^{61}$ Doses may be tapered off after the relapse, but most patients require permanent lowdose corticosteroids. Long-term corticosteroids may reduce the frequency and severity of relapses while not influencing the disease progression or prevent vital organ involvement. ${ }^{1-5}$

Corticosteroid-dependent or resistant diseases and/or lifethreatening diseases are an indication for immunosuppressive or immunomodulatory drugs. ${ }^{1-5}$ Their addition is necessary to control the disease activity or to spare corticosteroid dose and adverse events. ${ }^{43}$ Among these, colchicine, dapsone, methotrexate, cyclophosphamide, cyclosporine, chlorambucil, azathioprine, mycophenolate mofetil, intravenous immunoglobulin, minocycline, and leflunomide have been shown to be effective in some patients. ${ }^{3,44}$ Colchicine may be useful during remission phases of relapsing polychondritis. The efficacy of dapsone ${ }^{9,62,63}$ previously reported in patients without cardiac and respiratory involvement was questioned by Trentham and Le. ${ }^{5}$ However, reports showing its efficacy continue to be published. ${ }^{64}$ Moreover, the use of dapsone is associated with many adverse events. ${ }^{5}$ On the basis of the reported cases and in the absence of controlled trials, methotrexate would be the most effective immunosuppressive drug and would allow the best corticosteroid-sparing effect. ${ }^{5}$ Intravenous cyclophosphamide and plasmapheresis have been shown to be effective in life-threatening situations or organ-threatening diseases including acute airway obstruction, ophthalmic involvement, or glomerulonephritis. ${ }^{1,40,65,66}$ Immunosuppression-related infectious complications and undetected relapses after discontinuation of immunosuppressive drugs are largely responsible for the morbidity and mortality observed in these patients. ${ }^{44}$

Relapsing polychondritis has not remained on the margins of history with the introduction of biologics in our therapeutic arsenal. ${ }^{59}$ The alleged autoimmune nature of this disease was a major argument to justify the use of targeted biological therapies in patients with relapsing polychondritis refractory to the conventional immunosuppressive agents. Given the evidence of T-helper cell infiltration; ${ }^{27}$ the presence of antigen-antibody complexes in involved cartilage; the cellular humoral responses directed against type II collagen, matrilin, and other antigens in the sera; ${ }^{30-36}$ the frequency of HLA DR4; ${ }^{26,27}$ and the improvement after immunosuppressive therapy, ${ }^{1-5}$ it was logical to propose drugs blocking cellular pathways of immune responses and/or drugs targeted against B cells such as rituximab or abatacept. Furthermore, increased expression of cytokines in relapsing polychondritis including TNF $\alpha$, IL 1, and IL 6, particularly during relapse, ${ }^{33,55}$ can justify the use of specific inhibitors of these cytokines. However, no clinical trial is available to support an evidence-based medicine approach for the use of biologics in relapsing polychondritis. Therefore, the use of biologics is currently based on the estimation of disease activity and severity. ${ }^{59}$ Most of the biologics used and the strategies of treatment are borrowed from rheumatoid arthritis. ${ }^{59}$

The waltz with biologics was opened in 1991 with anti-CD4 monoclonal antibodies. A transient efficacy was observed in two patients with a rapid decline in circulating blood CD4 levels and a secondary return to normal levels more or less rapidly, without adverse event. ${ }^{67,68}$ It was not until the 2000s that watched a wave of publication on the efficacy of biologics in the management of relapsing polychondritis. Thus, anakinra, anti-TNF $\alpha$ (infliximab, etanercept, adalimumab, certolizumab pegol), abatacept, rituximab, and tocilizumab have been prescribed in many patients.

In a systematic review of the literature published in $2012,{ }^{59}$ we reached the following conclusions:

1) No clinical trials had been conducted with biologics in relapsing polychondritis. Five years after the recommendation was made, no randomized clinical trial has been conducted. 
2) The experience of biologics in relapsing polychondritis is limited, with only 62 prescriptions of at least one biologic in about 40 patients.

3) In almost all cases, biologics were prescribed after failure of at least one immunosuppressive drug.

4) Infliximab is the most widely used biologics. This trend continues to date, as shown in Table 3.

5) The endpoints and duration of follow-up were specific to each publication, and generally poorly defined, making the comparison of efficacy between different studies very difficult. Biologics in relapsing polychondritis were evaluated primarily on clinical outcomes, CRP levels, corticosteroids regimen, and thoracic CT scan. Only one study had clearly defined the endpoints during evaluation of the effects of rituximab in nine patients. In this study, disease activity was compared in the 6 months preceding rituximab administration and at 6 and 12 months after administration. Disease activity was evaluated on clinical features, CRP levels, thoracic CT scan, spirometry, corticosteroid regimen, and any change in immunosuppressive drugs. ${ }^{69}$

6) The safety profile of the different biologics was acceptable and similar to one observed in other pathologies such as rheumatoid arthritis. However, these data needed to be interpreted with caution given the scarce number of patients who received biologics in relapsing polychondritis. Furthermore, sepsis is a potentially fatal complication of biologics, and so their use requires full disclosure of potential risks to patients and careful patient monitoring. Prior use of corticosteroids and immunosuppressive drugs would increase the risk of severe infection. More, paradoxical effects have also been described. Three cases of relapsing polychondritis occurred within 2 months to 4 years in patients treated for ankylosing spondylitis with anti-TNF $\alpha$, requiring the use of corticosteroids to control the signs of relapsing polychondritis and the temporary suspension of biologics (etanercept) in two patients and the switch to infliximab from adalimumab in the third case..$^{70,71}$ Otherwise, a case of Sweet's syndrome occurred 1 week after initiating treatment with adalimumab for relapsing polychondritis, with no evidence of the association between these two diseases prior to initiation of biologics. ${ }^{72}$

7) There is no predictor of therapeutic response. Indeed, age, sex, duration of disease, CRP levels, or corticosteroid regimen do not seem to predict response to treatment, subject to limitations related to the comparison of reported cases.

8) The efficacy of biologics in relapsing polychondritis is mixed ranging from a good response to a complete lack of efficacy (Table 3). ${ }^{59}$ The number of lack of efficacy would probably be higher in real life because there is a little interest to publish negative results.

The updating of this data is in progress. However, we can already say that enthusiasm with biologics in relapsing polychondritis is increasing, given the number of patients currently under biologics. The number of biologics prescribed for relapsing polychondritis has increased from 62 in 2012 to about 185 in May 2017 (preliminary data). The biggest increase in the number of new prescriptions concerns adalimumab and tocilizumab, which currently occupies the second and third place of the most prescribed biologics, respectively. Infliximab remains the main prescribed biologics. In 2012, only two patients had been treated with tocilizumab and four with adalimumab. ${ }^{59}$ There is a long way to go before reaching randomized clinical trials in relapsing polychondritis. A pooling of data of teams taking care of these patients is desirable and necessary, like a recent French multicenter study on the efficacy of biologics in relapsing polychondritis. ${ }^{73}$ It would be important to choose the same endpoints and to determine the place of RPDAI in the evaluation of the therapeutic response. It is not ready

Table 3 Efficacy of biologics in relapsing polychondritis: 2017 update (preliminary reports)

\begin{tabular}{|c|c|c|c|c|c|c|c|c|}
\hline & \multicolumn{2}{|l|}{ Yes } & \multicolumn{2}{|c|}{ Partial } & \multicolumn{2}{|l|}{ No } & \multicolumn{2}{|c|}{ Total } \\
\hline & 2012 & 2017 & 2012 & 2017 & 2012 & 2017 & 2012 & 2017 \\
\hline Infliximab & 14 & 26 & 4 & 16 & 13 & 15 & 31 & 57 \\
\hline Etanercept & 5 & 7 & 0 & 9 & 3 & 3 & 8 & 19 \\
\hline Adalimumab & 2 & 12 & 0 & 17 & 2 & 3 & 4 & 32 \\
\hline Golimumab & 0 & 2 & 0 & 2 & 0 & 0 & 0 & 2 \\
\hline Certolizumab & 0 & I & 0 & 0 & 0 & 0 & 0 & I \\
\hline Rituximab & 0 & 2 & 2 & 7 & 9 & 9 & 11 & 18 \\
\hline Anakinra & 4 & 9 & 0 & 8 & I & I & 5 & 18 \\
\hline Tocilizumab & 2 & 14 & 0 & 14 & 0 & 0 & 2 & 30 \\
\hline Abatacept & I & 3 & 0 & 4 & 0 & I & I & 8 \\
\hline
\end{tabular}


to be done given the clinical polymorphism of this disease. Biologics cannot manage all the manifestations of relapsing polychondritis, constraining the clinicians to resort to certain nonpharmacological modalities in the present state of scientific knowledge.

Within the limits of the interpretation that can be given to cases reports, organ transplantation could be a promising route. Autologous stem-cell transplantation and allogeneic bone marrow transplantation allowed improvement of symptoms or complete remission in some patients. Then, hematopoietic transplantation may have curative potential for relapsing polychondritis. ${ }^{74-77}$

Invasive procedures are sometimes necessary for some patients. Again, no clinical trials were performed. Only reported cases of surgical procedure are available. The benefits of surgery care must be weighed against the patient's risk of infection, especially during acute relapse and/or corticosteroid intake. For tracheal collapse, stricture, or stenosis patients, tracheostomy is often performed. ${ }^{3,5,8,13}$ Thereafter, tracheal dilatation, stenting and assimilated, and reconstruction surgeries in the case of extensive lesions are sometimes necessary to save the patient. Pneumothorax and pneumomediastinum are adverse events described after stenting. In the case of sensorineural hearing loss, cochlear implants can restore hearing. Saddle nose deformity can be corrected by reconstructive surgeries with bone graft from the iliac crest; autoimmune nature of chondritis contraindicates cartilage grafting due to expected cartilage destruction. ${ }^{78}$ Heart valve replacement surgeries and aortic aneurysm surgery have been proposed to many patients. ${ }^{3}$

\section{Conclusion}

Relapsing polychondritis is a rare disorder that has for nearly a century kept a lot of secrets not yet explained. The challenges remain, both in the understanding of its pathophysiology and early diagnosis, the evaluation of its activity and prognosis, and its treatment. Possible solutions involve the sharing of data for relapsing polychondritis from worldwide reference centers. Thus, we will be able to evolve towards a better knowledge of its pathophysiology, the elaboration of new diagnosis criteria, which will include biological markers and imaging findings, the prediction of prognostic factors. Furthermore, randomized controlled trials are required for the definition of evidence-based treatment guidelines.

\section{Disclosure}

The authors report no conflicts of interest in this work.

\section{References}

1. Mathian A, Miyara M, Cohen-Aubart F, et al. Relapsing polychondritis: a 2016 update on clinical features, diagnostic tools, treatment and biological drug use. Best Pract Res Clin Rheumatol. 2016;30(2):316-333.

2. Longo L, Greco A, Rea A, Lo Vasco VR, De Virgilio A, De Vincentiis M. Relapsing polychondritis: a clinical update. Autoimmun Rev. 2016;15(6):539-543.

3. Sharma A, Gnanapandithan K, Sharma K, Sharma S. Relapsing polychondritis: a review. Clin Rheumatol. 2013;32(11):1575-1583.

4. Letko E, Zafirakis P, Baltatzis S, Voudouri A, Livir-Rallatos C, Foster CS. Relapsing polychondritis: a clinical review. Semin Arthritis Rheum. 2002;31(6):384-395.

5. Trentham DE, Le CH. Relapsing polychondritis. Ann Intern Med. 1998;129(2):114-122.

6. Jaksch-Wartenhorst R. Polychondropathia. Wien Arch F Inn Med. 1923;6:93-100.

7. Pearson CM, Kline HM, Newcomer VD. Relapsing polychondritis. N Engl J Med. 1960;263:51-58.

8. McAdam LP, O'Hanlan MA, Bluestone R, Pearson CM. Relapsing polychondritis: prospective study of 23 patients and a review of the literature. Medicine (Baltimore). 1976;55(3):193-215.

9. Damiani JM, Levine HL. Relapsing polychondritis - Report of ten cases. Laryngoscope. 1979;89(6 Pt 1):929-946.

10. Michet CJ Jr, McKenna CH, Luthra HS, O’Fallon WM. Relapsing polychondritis. Survival and predictive role of early disease manifestations. Ann Intern Med. 1986;104(1):74-78.

11. Francès C, el Rassi R, Laporte JL, Rybojad M, Papo T, Piette JC. Dermatologic manifestations of relapsing polychondritis. A study of 200 cases at a single center. Medicine (Baltimore). 2001;80(3):173-179.

12. Lin DF, Yang WQ, Zhang PP, Lv Q, Jin O, Gu JR. Clinical and prognostic characteristics of 158 cases of relapsing polychondritis in China and review of the literature. Rheumatol Int. 2016;36(7):1003-1009.

13. Dion J, Costedoat-Chalumeau N, Sène $D$, et al. Relapsing polychondritis can be characterized by three different clinical phenotypes: analysis of a recent series of 142 patients. Arthritis Rheumatol. 2016;68(12):2992-3001.

14. Kent PD, Michet CJ Jr, Luthra HS. Relapsing polychondritis. Curr Opin Rheumatol. 2004;16(1):56-61.

15. Horváth A, Páll N, Molnár K, et al. A nationwide study of the epidemiology of relapsing polychondritis. Clin Epidemiol. 2016;8:211-230.

16. Hazra N, Dregan A, Charlton J, Gulliford MC, D'Cruz DP. Incidence and mortality of relapsing polychondritis in the UK: a population-based cohort study. Rheumatology (Oxford). 2015;54(12):2181-2187.

17. Mathew SD, Battafarano DF, Morris MJ. Relapsing polychondritis in the Department of Defense population and review of the literature. Semin Arthritis Rheum. 2012;42(1):70-83.

18. Marshall J, Leroux DG. Chronic atrophic polychondritis, a South African case. S Afr Med J. 1964;38:527-529.

19. Gning SB, Perret JL, Cissokho B, Sane M, Ndoye B. [Atrophic polychondritis associated with rectal adenocarcinoma and muscular aponeurotic fibromatosis in an African woman]. Rev Med Interne. 2001;22(9):891-893. French.

20. Alissa H, Kadanoff R, Adams E. Does mechanical insult to cartilage trigger relapsing polychondritis? Scand J Rheumatol. 2001;30(5):311.

21. Cañas CA, Gómez AR, Echeverri AF, Quintana-Duque MA, Toro CE, Iglesias-Gamarra A. Patients with relapsing polychondritis and previous cartilage trauma present more autoimmunity phenomena. Rheumatol Int. 2012;32(2):541-543.

22. Furer V, Wieczorek RL, Pillinger MH. Bilateral pinna chondritis preceded by glucosamine chondroitin supplement initiation. Scand $J$ Rheumatol. 2011;40(3):241-243.

23. Berger R. Polychondritis resulting from intravenous substance abuse. Am J Med. 1988;85(3):415-417.

24. Cañas CA, Bonilla Abadía F. Local cartilage trauma as a pathogenic factor in autoimmunity (one hypothesis based on patients with relapsing polychondritis triggered by cartilage trauma). Autoimmune Dis. 2012;2012: 453698 . 
25. Zeuner M, Straub RH, Rauh G, Albert ED, Schölmerich J, Lang B. Relapsing polychondritis: clinical and immunogenetic analysis of 62 patients. J Rheumatol. 1997;24(1):96-101.

26. Lang B, Rothenfusser A, Lanchbury JS, et al. Susceptibility to relapsing polychondritis is associated with HLA-DR4. Arthritis Rheum. 1993;36(5):660-664.

27. Terao C, Yoshifuji H, Yamano Y, et al. Genotyping of relapsing polychondritis identified novel susceptibility HLA alleles and distinct genetic characteristics from other rheumatic diseases. Rheumatology (Oxford). 2016;55(9):1686-1692.

28. Alsalameh S, Mollenhauer J, Scheuplein F, et al. Preferential cellular and humoral immune reactivities to native and denatured collagen types IX and XI in a patient with fatal relapsing polychondritis. J Rheumatol. 1993;20(8):1419-1424.

29. Stabler T, Piette JC, Chevalier X, Marini-Portugal A, Kraus VB. Serum cytokine profiles in relapsing polychondritis suggest monocyte/macrophage activation. Arthritis Rheum. 2004;50(11):3663-3667.

30. Foidart JM, Abe S, Martin GR, et al. Antibodies to type II collagen in relapsing polychondritis. $N$ Engl J Med. 1978;299(22):1203-1207.

31. Terato K, Shimozuru Y, Katayama K, et al. Specificity of antibodies to type II collagen in rheumatoid arthritis. Arthritis Rheum. 1990;33(10): 1493-1500.

32. Burkhardt H, Koller T, Engström A, et al. Epitope-specific recognition of type II collagen by rheumatoid arthritis antibodies is shared with recognition by antibodies that are arthritogenic in collagen-induced arthritis in the mouse. Arthritis Rheum. 2002;46(9):2339-2348.

33. Yang CL, Brinckmann J, Rui HF, et al. Autoantibodies to cartilage collagens in relapsing polychondritis. Arch Dermatol Res. 1993; 285(5):245-249.

34. Hansson AS, Heinegård D, Holmdahl R. A new animal model for relapsing polychondritis, induced by cartilage matrix protein (matrilin-1). J Clin Invest. 1999;104(5):589-598.

35. Hansson AS, Heinegård D, Piette JC, Burkhardt H, Holmdahl R. The occurrence of autoantibodies to matrilin 1 reflects a tissue-specific response to cartilage of the respiratory tract in patients with relapsing polychondritis. Arthritis Rheum. 2001;44(10):2402-2412.

36. Buckner JH, Wu JJ, Reife RA, Terato K, Eyre DR. Autoreactivity against matrilin-1 in a patient with relapsing polychondritis. Arthritis Rheum. 2000;43(4):939-943.

37. Meyer O, Semmache M, Cyna J, Mitrovic D, Ryckewaert A. [Anticollagen antibodies. Their detection in rheumatoid polyarthritis, chronic atrophic polychondritis and various chronic inflammatory rheumatism]. Rev Rhum Mal Osteoartic. 1983;50(7):493-499. French.

38. Taneja V, Griffiths M, Behrens M, Luthra HS, David CS. Auricular chondritis in NOD.DQ8.Abetao (Ag7-/-) transgenic mice resembles human relapsing polychondritis. J Clin Invest. 2003;112(12):1843-1850.

39. Menge T, Rzepka R, Melchers I. Monoclonal autoantibodies from patients with autoimmune diseases: specificity, affinity and crossreactivity of MAbs binding to cytoskeletal and nucleolar epitopes, cartilage antigens and mycobacterial heat-shock protein 60. Immunobiology. 2002;205(1):1-16.

40. Belot A, Collardeau-Frachon S, Bellil D, Descours G, Gillet Y. It sounds like a relapsing polychondritis. Lancet Infect Dis. 2013;13(7):638.

41. File I, Trinn C, Mátyus Z, Ujhelyi L, Balla J, Mátyus J. Relapsing polychondritis with p-ANCA associated vasculitis: which triggers the other? World J Clin Cases. 2014;2(12):912-917.

42. Shimizu J, Oka H, Yamano Y, Yudoh K, Suzuki N. Cutaneous manifestations of patients with relapsing polychondritis: an association with extracutaneous complications. Clin Rheumatol. 2016;35(3):781-783.

43. Pruthi P, Munganda H, Bangia A, Rani U, Budhiraja R, Brajpuriya S. Leprosy with atypical skin lesions masquerading as relapsing polychondritis. Case Rep Infect Dis. 2016;2016:7802423.

44. Chang-Miller A, Okamura M, Torres VE, et al. Renal involvement in relapsing polychondritis. Medicine (Baltimore). 1987;66(3):202-217.

45. Riccieri V, Spadaro A, Taccari E, Zoppini A. A case of relapsing polychondritis: pathogenetic considerations. Clin Exp Rheumatol. 1988;6(1):95-96.
46. Ouchi N, Uzuki M, Kamataki A, Miura Y, Sawai T. Cartilage destruction is partly induced by the internal proteolytic enzymes and apoptotic phenomenon of chondrocytes in relapsing polychondritis. J Rheumatol. 2011;38(4):730-737.

47. Nakano K, Aritomi T, Ohkubo N, Tanaka Y. Relapsing polychondritis diagnosed by fusion images of gallium- 67 on single photon emission computed tomography/computed tomography. Arthritis Rheumatol. Epub 2017 Aug 22.

48. Lei W, Zeng H, Zeng DX, et al. (18)F-FDG PET-CT: a powerful tool for the diagnosis and treatment of relapsing polychondritis. Br J Radiol. 2016;89(1057):20150695.

49. Wang J, Li S, Zeng Y, Chen P, Zhang N, Zhong N. ${ }^{18} \mathrm{~F}-\mathrm{FDG}$ PET/CT is a valuable tool for relapsing polychondritis diagnose and therapeutic response monitoring. Ann Nucl Med. 2014;28(3):276-284.

50. Wang J, Liu X, Pu C, Chen Y. 18F-FDG PET/CT is an ideal imaging modality for the early diagnosis of relapsing polychondritis: a case report. Medicine (Baltimore). 2017;96(30):e7503.

51. Zhou H, Su M, Li L. 18F-FDG PET/CT imaging of relapsing polychondritis: a case report. Medicine (Baltimore). 2016;95(33):e4496.

52. Ikeda S, Arita M, Ikeo S, et al. Chronological assessment of airway lesions in relapsing polychondritis by positron emission tomography. Intern Med. 2015;54(9):1099-1102.

53. Thaiss WM, Nikolaou K, Spengler W, et al. Imaging diagnosis in relapsing polychondritis and correlation with clinical and serological data. Skeletal Radiol. 2016;45(3):339-346.

54. Pallo PAO, Levy-Neto M, Pereira RMR, Shinjo SK. Relapsing polychondritis: prevalence of cardiovascular diseases and its risk factors, and general disease features according to gender. Rev Bras Reumatol Engl Ed. 2017;57(4):338-345.

55. Kraus VB, Stabler T, Le ET, Saltarelli M, Allen NB. Urinary type II collagen neoepitope as an outcome measure for relapsing polychondritis. Arthritis Rheum. 2003;48(10):2942-2948.

56. Kempta Lekpa F, Piette JC, Bastuji-Garin S, et al. Serum cartilage oligomeric matrix protein (COMP) level is a marker of disease activity in relapsing polychondritis. Clin Exp Rheumatol. 2010;28(4):553-555.

57. Sato T, Yamano Y, Tomaru U, et al. Serum level of soluble triggering receptor expressed on myeloid cells-1 as a biomarker of disease activity in relapsing polychondritis. Mod Rheumatol. 2014;24(1):129-136.

58. Arnaud L, Devilliers H, Peng SL, et al; RPDAI study group. The Relapsing Polychondritis Disease Activity Index: development of a disease activity score for relapsing polychondritis. Autoimmun Rev. 2012;12(2):204-209.

59. Kemta Lekpa F, Kraus VB, Chevalier X. Biologics in relapsing polychondritis: a literature review. Semin Arthritis Rheum. 2012;41(5):712-719.

60. DaCunha M, Christensen LC, Aires D, Liu D. Intralesional corticosteroid therapy for relapsing polychondritis. JAm Acad Dermatol. 2017;76(5): e165-e166.

61. Wasano K, Tomisato S, Yamamoto S, Suzuki N, Kawasaki T, Ogawa K. Successful continual intratympanic steroid injection therapy in a patient with refractory sensorineural hearing loss accompanied by relapsing polychondritis. Auris Nasus Larynx. 2017;44(4):489-492.

62. Martin J, Roenigk HH, Lynch W, Tingwald FR. Relapsing polychondritis treated with dapsone. Arch Dermatol. 1976;112(9):1272-1274.

63. Barranco VP, Minor DB, Soloman H. Treatment of relapsing polychondritis with dapsone. Arch Dermatol. 1976;112(9):1286-1288.

64. Lu PH, Lin YC, Wu YH. Relapsing polychondritis complicated with Sweet's syndrome and normolipemic neutrophilic xanthomatosis successfully treated by dapsone. Int J Dermatol. 2011;50(2):212-214.

65. Almackenzie M, Alharbi A, Alhassan S, Cook E, Altorok N. Successful treatment of central nervous system vasculitis associated with relapsing polychondritis with cyclophosphamide. Am J Med Sci. 2017;353(5):495-497.

66. Sainz-de-la-Maza M, Molina N, Gonzalez-Gonzalez LA, Doctor PP, Tauber J, Foster CS. Scleritis associated with relapsing polychondritis. Br J Ophthalmol. 2016;100(9):1290-1294.

67. van der Lubbe PA, Miltenburg AM, Breedveld FC. Anti-CD4 monoclonal antibody for relapsing polychondritis. Lancet. 1991;337(8753):1349. 
68. Choy EH, Chikanza IC, Kingsley GH, Panayi GS. Chimaeric antiCD4 monoclonal antibody for relapsing polychondritis. Lancet. 1991;338(8764):450.

69. Leroux G, Costedoat-Chalumeau N, Brihaye B, et al. Treatment of relapsing polychondritis with rituximab: a retrospective study of nine patients. Arthritis Rheum. 2009;61(5):577-582.

70. Hernández MV, Ruiz-Esquide V, Gómez-Caballero ME, Gómez-Puerta JA, Cañete JD, Sanmartí R. Relapsing polychondritis: a new adverse event secondary to the use of tumour necrosis factor antagonists? Rheumatology (Oxford). 2011;50(8):1523-1525.

71. Azevedo VF, Galli NB, Kleinfelder AD, D'Ippolito JF, Gulin Tolentino A, Paiva E. Relapsing polychondritis in a patient with ankylosing spondylitis using etanercept. Case Rep Rheumatol. 2014;2014:353782.

72. Keidel S, McColl A, Edmonds S. Sweet's syndrome after adalimumab therapy for refractory relapsing polychondritis. BMJ Case Rep. 2011;2011. pii: bcr1020114935.

73. Moulis G, Pugnet G, Costedoat-Chalumeau N, et al. Efficacy and safety of biologics in relapsing polychondritis: a national multicentre study in France [abstract]. Arthritis Rheumatol. 2016;68(Suppl 10). Abstract number: 1329.

74. Tomomatsu J, Hamano Y, Ando J, Komatsu N, Sugimoto K. Nonmyeloablative allogenic BMT for myelodysplastic syndrome successfully controlled accompanying relapsing polychondritis. Bone Marrow Transplant. 2012;47(5):742-743.
75. Daikeler T, Kötter I, Bocelli Tyndall C, et al; EBMT Autoimmune Diseases Working Party. Haematopoietic stem cell transplantation for vasculitis including Behcet's disease and polychondritis: a retrospective analysis of patients recorded in the European Bone Marrow Transplantation and European League Against Rheumatism databases and a review of the literature. Ann Rheum Dis. 2007;66(2):202-207.

76. Kötter I, Daikeler T, Amberger C, Tyndall A, Kanz L. Autologous stem cell transplantation of treatment-resistant systemic vasculitis--a single center experience and review of the literature. Clin Nephrol. 2005;64(6) 485-489.

77. Rosen O, Thiel A, Massenkeil G,. Autologous stem-cell transplantation in refractory autoimmune diseases after in vivo immunoablation and ex vivo depletion of mononuclear cells. Arthritis Res. 2000;2(4): 327-336.

78. Haug MD, Witt P, Kalbermatten FD, Rieger UM, Schaefer DJ, Pierer G. Severe respiratory dysfunction in a patient with relapsing polychondritis: should we treat the saddle nose deformity? J Plast Reconstr Aesthet Surg. 2009;62(2):e7-e10.

79. Club Rhumatismes et Inflammations. [website on the Internet]. Available from http://www.cri-net.com/autres-projets/base_images/display_rub. asp?rub=poly_atro. Accessed December 22, 2017.
Open Access Rheumatology: Research and Reviews

\section{Publish your work in this journal}

Open Access Rheumatology: Research and Reviews is an international, peerreviewed, open access journal publishing original research, reports, editorials, reviews and commentaries on all aspects of clinical and experimental rheumatology in the clinic and laboratory including the following topics: Pathology, pathophysiology of rheumatological diseases; Investigation, treatment and

\section{Dovepress}

management of rheumatological diseases; Clinical trials and novel pharmacologi$\mathrm{cal}$ approaches for the treatment of rheumatological disorders. The manuscript management system is completely online and includes a very quick and fair peer-review system, which is all easy to use. Visit http://www.dovepress.com/ testimonials.php to read real quotes from published authors. 